\title{
Modifiers of breast and ovarian cancer risks for BRCA1 and BRCA2 mutation carriers
}

\author{
Roger L Milne1,2 and Antonis C Antoniou ${ }^{3}$ \\ ${ }^{1}$ Cancer Epidemiology Centre, Cancer Council Victoria, Melbourne, Australia \\ ${ }^{2}$ Centre for Epidemiology and Biostatistics, Melbourne School of Population and Global Health, \\ University of Melbourne, Parkville, Victoria, Australia \\ ${ }^{3}$ Centre for Cancer Genetic Epidemiology, Department of Public Health and Primary Care, \\ University of Cambridge, Cambridge, UK
}

Correspondence should be addressed to A C Antoniou Email aca20@medschl.cam.ac.uk

\begin{abstract}
Pathogenic mutations in BRCA1 and BRCA2 are associated with high risks of breast and ovarian cancer. However, penetrance estimates for mutation carriers have been found to vary substantially between studies, and the observed differences in risk are consistent with the hypothesis that genetic and environmental factors modify cancer risks for women with these mutations. Direct evidence that this is the case has emerged in the past decade, through large-scale international collaborative efforts. Here, we describe the methodological challenges in the identification and characterisation of these risk-modifying factors, review the latest evidence on genetic and lifestyle/hormonal risk factors that modify breast and ovarian cancer risks for women with BRCA1 and BRCA2 mutations and outline the implications of these findings for cancer risk prediction. We also review the unresolved issues in this area of research and identify strategies of clinical implementation so that women with BRCA1 and BRCA2 mutations are no longer counselled on the basis of 'average' risk estimates.
\end{abstract}

Endocrine-Related Cancer (2016) 23, T69-T84

\section{Introduction}

Pathogenic mutations in BRCA1 and BRCA2 are associated with high risks of breast and ovarian cancer. Based on conservative estimates (Antoniou et al. 2008a), approximately 1 in 240 individuals in the population carry one of these mutations. BRCA1 and BRCA2 mutations explain 5-10\% of breast cancers diagnosed in women before age 40 years (Peto et al. 1999, Anglian Breast Cancer Study Group 2000) and 11-14\% of highgrade serous ovarian cancers (Alsop et al. 2012, Song et al. 2014). They account for $17-20 \%$ of the familial risk of breast cancer (Peto et al. 1999, Anglian Breast Cancer Study Group 2000, Mavaddat et al. 2010) and $\sim 24 \%$ of the familial risk of ovarian cancer (Jervis et al. 2014). Genetic testing for BRCA1 and BRCA2 mutations is widely available and has become an integral part of genetic counselling and oncologic and gynaecologic practice (Karlan et al. 2007). Test results are often used to inform recommendations about the most appropriate treatment or clinical management options for women. To provide optimal advice to women found to carry mutations in these genes, particularly given that prevention options can have significant side effects, precise estimates of associated age-specific cancer risks are required.

This paper forms part of a thematic review section on 20 Years of BRCA 1 and 2 The Guest Editors for this section were Kokichi Sugano and William Foulkes. 
Estimates of the cumulative risk of cancer (to age 70 years) for BRCA1 and BRCA2 mutation carriers have been found to vary substantially between studies. Retrospective studies have reported estimates for breast cancer that range from 40 to $87 \%$ for BRCA1 mutation carriers and from 27 to $84 \%$ for $B R C A 2$ mutation carriers (Easton et al. 1995, Ford et al. 1998, Hopper et al. 1999, Antoniou et al. 2003, 2005b, 2008a,b, Chen et al. 2006, Begg et al. 2008, Milne et al. 2008, Brohet et al. 2014, GabaiKapara et al. 2014). The corresponding ovarian cancer risk estimates vary from 16 to $68 \%$ for $B R C A 1$ mutation carriers and from 11 to $27 \%$ for BRCA2 mutation carriers. Although the observed variability in risk estimates could be partly due to different sampling schemes across studies, the risk estimates within studies have been found to vary by the age of diagnosis and type of cancer in close relatives (Antoniou et al. 2003, Begg et al. 2008) and to be higher for women born in more recent decades (Antoniou et al. 2003, Simchoni et al. 2006, Brohet et al. 2014). These observations suggest that genetic factors, including genotype-phenotype correlations (i.e. mutation-specific risks), and environmental or reproductive/lifestyle factors, modify cancer risks for mutation carriers.

Retrospective, family-based studies have inherent limitations including ascertainment biases and biases due to inaccuracies in the reporting of family history. Many of these are overcome by prospective studies, but those published to date have been based on relatively small sample sizes (with fewer than 65 incident cancers); as a result, estimates remain relatively imprecise (Mavaddat et al. 2013, Senst et al. 2013, Evans et al. 2014). These prospective studies were enriched for families that met high- or moderate-risk screening criteria presenting to genetic clinics, and the risk estimates were generally higher than those from retrospective population-based studies. This observation is also consistent with the existence of genetic modifiers that aggregate in multiple-case families.

In the past decade, through large international collaborative efforts and advances in genotyping technologies, direct evidence has emerged that there are genetic and lifestyle/hormonal factors that modify breast and ovarian cancer risks for BRCA1 and BRCA2 mutation carriers. These findings suggest that it is no longer appropriate to counsel BRCA1 and BRCA2 mutation carriers on the basis of 'average' risk estimates. Moreover, the development of cost-effective sequencing technologies and gene panel testing are likely to enable more widespread BRCA1 and BRCA2 mutation screening, not necessarily restricted to those with a strong family history of breast or ovarian cancer, as exemplified by the 100,000 genomes project in the United Kingdom (http://www.genomicsengland.co.uk). Thus, it is critical that we improve our ability to estimate cancer risks for carriers in all contexts. We should aim to be able to provide comprehensive counselling based on estimates that consider: the gene mutated and the position and functional effect of the mutation, as well as family history of cancer and all genetic and lifestyle/hormonal factors that modify risk for mutation carriers.

Here, we review the latest evidence on genetic and lifestyle/hormonal risk factors that modify breast and ovarian cancer risks for women with BRCA1 and BRCA2 mutations and outline their implications for cancer risk prediction. However, first we summarise the methodological challenges in the identification and characterisation of such modifiers of risk.

\section{Challenges in the identification and characterisation of risk modifiers for mutation carriers}

In contrast to epidemiological and genetic association studies in the general population, identifying and characterising genetic and lifestyle cancer risk-modifying factors for BRCA1 and BRCA2 mutation carriers pose a number of methodological and analytical challenges. The optimal study design for studying factors that modify cancer risks is a prospective cohort in which unaffected mutation carriers are followed up over time to observe prospectively who goes on to develop cancer. This study design overcomes issues of ascertainment, recall and testing bias (Antoniou et al. 2005a, Whittemore 2007, Heemskerk-Gerritsen et al. 2015b), but many years of follow-up are required for a sufficient number of incident cancer cases to occur to obtain adequately precise risk estimates. Furthermore, a large fraction of mutation carriers opt for risk-reducing surgery and hence are removed from the 'at-risk' cohort. To date, findings from only a limited number of prospective studies have been reported, and these were based on small sample sizes (Mavaddat et al. 2013, Senst et al. 2013, Evans et al. 2014). An alternative approach would be to screen for $B R C A 1$ and $B R C A 2$ mutations in large-scale population-based casecontrol studies. However, BRCA1 and BRCA2 mutations are rare in the population, and large sample sizes of affected and unaffected individuals are required. Until recently, such designs have been prohibitively expensive, with the exception of studies of founder mutations in the Ashkenazi, Icelandic and Polish populations. However, with advances in sequencing technologies,

Published by Bioscientifica Ltd. 
population-based case-control studies are likely to become feasible in the context of large international consortia such as the Breast/Ovarian Cancer Association Consortia (BCAC: http://bcac.ccge.medschl.cam.ac.uk; OCAC: http://apps.ccge.medschl.cam.ac.uk/consortia/ocac/).

Given these challenges, most published studies to date have identified affected and unaffected BRCA1 and $B R C A 2$ mutation carriers through ongoing genetic testing programmes. However, genetic testing is targeted at women with a strong family history of cancer and young affected women are more likely than unaffected women to get tested first. Therefore, the sampling of mutation carriers is not random with respect to their disease status and standard methods of analysis can yield biased relative risk estimates (Antoniou et al. 2005a, Barnes et al. 2012). A number of different analytical approaches have been proposed to adjust for the sampling frame (Antoniou et al. 2005a, Whittemore 2007, Barnes et al. 2012), and these have been applied in several, but not all, large-scale association analyses.

Retrospective epidemiological risk factor studies may be subject to selection bias, information bias or confounding. In retrospective studies of mutation carriers, selection bias may particularly be problematic for the assessment of reproductive history; the decision a woman makes about being tested may be influenced by both whether or not she has children and whether she has been diagnosed with breast or ovarian cancer (Antoniou et al. 2009a). As most of the studies performed to date on lifestyle/hormonal risk modifiers for BRCA1 and BRCA2 mutation carriers have been retrospective and based on relatively small sample sizes, these limitations apply to practically all published findings. In general, studies of genetic modifiers of cancer risk for mutation carriers are less likely to be susceptible to such biases. However, in studies in which family history or the disease phenotypes play a role in the sample selection, some biases may arise in the relative risk estimates if these factors are not correctly accounted for in the analysis.

\section{Genetic modifiers}

Until relatively recently, the approach taken to investigate common polymorphisms that modify breast and ovarian cancer risk for mutation carriers was to conduct hypothesis-based association studies focused on genes considered biologically likely to be involved in disease aetiology. These studies assessed putative functional variants in genes in candidate pathways such as DNA repair, steroid hormone metabolism and environmental carcinogen detoxification. The advantage of this approach is that the biological interpretation of positive findings is relatively straightforward. However, analogous to research into common breast and ovarian cancer susceptibility variants in the general population, these candidate gene studies generally gave contradictory results across multiple small-scale studies and have not been convincingly replicated in more adequately powered studies (Breast Cancer Association Consortium 2006, Chenevix-Trench et al. 2007). Another limitation of this candidate gene approach is that it was based on what would now be considered a narrow consideration of what might be a functional variant, focused primarily on the coding sequence of genes.

The Consortium of Investigators of Modifiers of BRCA1/2 (CIMBA) was established to evaluate reliably the common genetic modifiers of breast and ovarian cancer risk for mutation carriers. With advances in technology and concurrent dramatic reduction in the cost of large-scale genotyping, candidate gene approaches to study the genetic epidemiology of complex disease have largely been replaced by hypothesis-free genomewide association studies (GWAS). Genotypes at many millions of common variants across the genome can be genotyped or imputed with high accuracy using largescale genotyping arrays, using reference panels from the 1000 Genomes Project (Auton et al. 2015). This approach has been applied with great success in cancer epidemiology in the general population, with GWAS having identified more than 100 common susceptibility variants for breast cancer (Cox et al. 2007, Easton et al. 2007, Hunter et al. 2007, Stacey et al. 2007, 2008, Ahmed et al. 2009, Thomas et al. 2009, Antoniou et al. 2010b, Turnbull et al. 2010, Cai et al. 2011, Fletcher et al. 2011, Haiman et al. 2011, Ghoussaini et al. 2012, Hein et al. 2012, Long et al. 2012, Siddiq et al. 2012, Bojesen et al. 2013, French et al. 2013, Garcia-Closas et al. 2013, Gaudet et al. 2013, Meyer et al. 2013, Michailidou et al. 2013, 2015, Cai et al. 2014, Milne et al. 2014a, Orr et al. 2015, Couch et al. 2016, Dunning et al. 2016, Lawrenson et al. 2016, Zheng et al. 2009) and 22 for ovarian cancer (Song et al. 2009, Bolton et al. 2010, Goode et al. 2010, Bojesen et al. 2013, Permuth-Wey et al. 2013, Pharoah et al. 2013, Shen et al. 2013, Kuchenbaecker et al. 2015).

In this context, within CIMBA, four approaches have been applied to identify loci associated with breast and ovarian cancer for mutation carriers: (i) GWAS for breast and ovarian cancer specifically performed in samples of BRCA1 and BRCA2 mutation carriers (Antoniou et al. 2010b, Couch et al. 2013, Gaudet et al. 2013); (ii) association

Published by Bioscientifica Ltd 
studies to assess common breast and ovarian cancer susceptibility alleles identified in the general population as potential modifiers of risk for mutation carriers (Antoniou et al. 2008b, 2009b, 2010a, 2011, 2012, Ramus et al. 2010, Couch et al. 2012, Ramus et al. 2012, Couch et al. 2013, Kuchenbaecker et al. 2014); (iii) meta-analyses of GWAS performed in BRCA1 and BRCA2 mutation carriers with GWAS of related phenotypes in the general population (for example, combining studies of breast cancer risk for BRCA1 mutation carriers with those of oestrogen receptor-negative breast cancer in general population or studies of ovarian cancer risk for BRCA1 and BRCA2 mutation carriers with GWAS of serous ovarian cancer in the general population) (Kuchenbaecker et al. 2015, Couch et al. 2016); and iv) finescale mapping of risk-modifying loci identified through GWAS approaches to fully characterise the associations with all genetic variants at these loci (Bojesen et al. 2013, Dunning et al. 2016, Lawrenson et al. 2016).

The third of these approaches stems from results from the first two, suggesting that many of the loci found to modify cancer risks for mutation carriers coincide with those found in GWAS of the general population (predominantly non-carriers)(Garcia-Closas et al. 2013, Michailidou et al. 2013). More specifically, susceptibility loci for overall and oestrogen receptor (ER)-positive breast cancer for women in the general population tend to be associated with overall breast cancer risk for BRCA2 mutation carriers (who mostly (70-80\%) develop ER-positive disease (Mavaddat et al. 2012)), whereas those for ER-negative breast cancer tend to be associated with overall risk for BRCA1 mutation carriers (who mostly (70-80\%) develop ER-negative disease (Mavaddat et al. 2012)) (Milne \& Antoniou 2011, Kuchenbaecker et al. 2014). A systematic evaluation of the associations of 74 known breast cancer susceptibility alleles found that their associations with ER-positive breast cancer for BRCA1 and $B R C A 2$ mutation carriers were more consistent with the associations of these SNPs with ER-positive breast cancer in the general population. Furthermore, the associations of these SNPs with ER-negative breast cancer for BRCA1 and BRCA2 mutation carriers were more consistent with the associations of the SNPs with ER-negative breast cancer in the general population (Kuchenbaecker et al. 2014). Similarly, common variants associated with the risk of serous ovarian cancer in the general population are associated with overall ovarian cancer risk for carriers of mutations in both genes (approximately two-thirds of whom develop serous disease) (Mavaddat et al. 2012). These observations have two important implications. The first underpins approach (ii) listed above, and is that common genetic modifiers of breast and ovarian cancer risk for BRCA1 and BRCA2 mutation carriers can be identified through GWAS of overall disease or disease subtypes in the general population, which have far greater statistical power due to much greater sample sizes. Therefore, common genetic variants identified from population-based GWAS have a high prior probability of association with risk for mutation carriers and more liberal significance thresholds can be used to assess the associations of such variants in mutation carriers. The second implication informs approach (iii) above, and is that an optimal strategy for the identification of novel genetic modifiers is meta-analysis of GWAS of these related phenotypes (Kuchenbaecker et al. 2015, Couch et al. 2016). Nevertheless, there appear to be some loci that modify breast or ovarian cancer risk specifically for BRCA1 and BRCA2 mutation carriers, showing no evidence of association with risk in the general population (Couch et al. 2013, Gaudet et al. 2013). As summarised in Table 1, to date, a total of 26 and 16 single nucleotide polymorphisms (SNPs) associated with breast cancer risk for BRCA1 and BRCA2 mutation carriers, respectively, have been identified. The corresponding numbers for ovarian cancer risk are 11 and 13 . The associated effect sizes are small, with estimated relative risks per copy of the minor allele in the range 1.05-1.26 for breast cancer and 1.03-1.48 for ovarian cancer. These genetic modifiers are estimated to account for a relatively small proportion $(<10 \%)$ of the modifying genetic variance for BRCA1 and BRCA2 mutation carriers (based on estimates of the modifying variance from segregation analyses), and it is predicted that residual family history remains an important risk-modifying factor (Couch et al. 2013, 2016, Gaudet et al. 2013, Kuchenbaecker et al. 2015), as recently demonstrated in the general population (Mavaddat et al. 2015). However, the joint effects of SNPs and family history have not been estimated for BRCA1 and BRCA2 mutation carriers. These are required before these genetic susceptibility findings can be implemented in the genetic counselling process.

One of the limitations of the hypothesis-free approach underlying GWAS is that they identify the associations with genetic markers, with no a priori knowledge of what functional variants might explain these associations or the genes or genetic pathways through which they might act. Thus, establishing the biological mechanisms underpinning GWAS associations has proven to be particularly challenging. Fine-mapping studies, in which a much denser selection of SNPs in susceptibility loci is genotyped and analysed using multivariable (conditional)

Published by Bioscientifica Ltd 
Table 1 Approaches adopted to identify independent genetic modifiers of breast and ovarian cancer risk for BRCA1 and BRCA2 mutation carriers.

\begin{tabular}{|c|c|c|c|c|c|}
\hline \multirow[b]{2}{*}{ Approach } & \multirow[b]{2}{*}{$P$ value threshold } & \multicolumn{2}{|c|}{ Breast cancer } & \multicolumn{2}{|c|}{ Ovarian cancer } \\
\hline & & BRCA1 & BRCA2 & BRCA1 & BRCA2 \\
\hline \multirow[t]{3}{*}{ GWAS of mutation carriers } & $* P<5 \times 10^{-8}$ & 2 SNPs $^{a, b}$ & $1 \mathrm{SNPc}$ & $2 \mathrm{SNPs}^{\mathrm{b}}$ & None \\
\hline & & MAF (0.26-0.47) & MAF (0.35) & MAF (0.20-0.48) & \\
\hline & & HR (1.14-1.26) & HR (1.18) & HR (1.20-1.26) & \\
\hline \multirow{3}{*}{$\begin{array}{l}\text { Candidates from other } \\
\text { breast cancer GWAS }\end{array}$} & $\# P<0.05$ & 16 SNPs d,e,f,g,h,i & 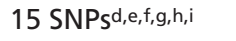 & 4 SNPsj,k,l & 7 SNPsb,j,k,l \\
\hline & & MAF (0.08-0.47) & MAF (0.08-0.49) & MAF (0.08-0.13) & MAF (0.08-0.30) \\
\hline & & HR (1.05-1.21) & HR (1.06-1.24) & HR (1.11-1.25) & HR (1.16-1.48) \\
\hline \multirow[t]{3}{*}{ Meta-analysis } & ${ }^{\dagger} P<5 \times 10^{-8}$ & 2 SNPsm & Not done & 5 SNPs $^{n}$ & 6 SNPsn \\
\hline & & MAF (0.24-0.34) & & MAF (0.15-0.31) & $\operatorname{MAF}(0.15-0.31)$ \\
\hline & & HR (1.08-1.09) & & HR (1.08-1.15) & HR (1.03-1.35) \\
\hline \multirow[t]{3}{*}{ Fine-mapping } & ${ }^{\ddagger} P<5 \times 10^{-4}$ & 6 SNPso,p,q & Not done & Not done & Not done \\
\hline & & MAF (0.07-0.50) & & & \\
\hline & & HR (1.07-1.12) & & & \\
\hline
\end{tabular}

BRCA1, BRCA1 mutation carriers; BRCA2, BRCA2 mutation carriers; SNP, single nucleotide polymorphism; MAF, range of minor allele frequencies; $\mathrm{HR}$, range of hazard ratio estimates.

*Classical genome-wide statistical significance; \#Nominal statistical significance, given the high prior probability of association based on evidence (at $P<5 \times 10^{-8}$ ) from other GWAS; ${ }^{+}$Genome-wide statistical significance in meta-analysis and HR estimate consistent in direction with findings for non-carriers; ${ }^{*}$ Statistical significance assessed in mutation carriers after adjustment for the top hit(s).

aAntoniou et al. (2010b); bCouch et al. (2013); cGaudet et al. (2013); dAntoniou et al. (2012); eKuchenbaecker et al. (2014); fAntoniou et al. (2011); gAntoniou et al. (2010a); hAntoniou et al. (2009b); 'Antoniou et al. (2008b); iRamus et al. (2012); 'Couch et al. (2012); 'Ramus et al. (2010); mCouch et al. (2016); nKuchenbaecker et al. (2015); 'Dunning et al. (2016); pLawrenson et al. (2016); aBojesen et al. (2013).

models, can highlight potentially causal variants, although extensive laboratory work is often required to demonstrate their function. These experiments are not feasible for all loci, and those that are, are often laborious and sometimes equivocal in identifying a single causal variant or even a single target gene (Dunning et al. 2016, Lawrenson et al. 2016). These fine-mapping studies often identify additional independent associations.

\section{Genotype-phenotype correlations}

Soon after the discovery of $B R C A 1$ and $B R C A 2$, observations in families carrying mutations provided evidence that breast and ovarian cancer risks for BRCA1 and BRCA2 mutations may vary depending on the location of the mutation in each gene (Gayther et al. 1995, 1997). Using a larger dataset, the Breast Cancer Linkage Consortium (BCLC) (Thompson et al. 2002) reported that the ratio of ovarian to breast cancers associated with mutations in a central region of $B R C A 1$ was significantly higher than that for mutations outside this region. This was attributed to a lower risk of breast cancer associated with mutations in this region, compared with mutations outside the region, and to a lower ovarian cancer risk for mutations in the 3' end up to nucleotide 4191 region, compared to mutations in the rest of the gene. A study of probands with ovarian cancer (Risch et al. 2001) reported that the risk of breast cancer for $B R C A 1$ mutation carriers increases with mutation position, from $5^{\prime}$ to $3^{\prime}$. Similarly, mutations in a central region of exon 11 (the "Ovarian Cancer Cluster Region" OCCR) of BRCA2 were found by the BCLC to be associated with a higher ratio of ovarian to breast cancer. Mutations in the OCCR were found to be associated with both a lower risk of breast cancer and a higher risk of ovarian cancer relative to $B R C A 2$ mutations outside this region (Thompson et al. 2001). Risch and coworkers (Risch et al. 2001) found that only mutations outside the OCCR of BRCA2 were associated with increased breast cancer risk. Subsequent penetrance studies for BRCA1 and $B R C A 2$ mutation carriers found supporting, but non-significant, evidence for the risk patterns observed in the BCLC analyses (Antoniou et al. 2003, Brohet et al. 2014), although one did not observe differences in risk (Milne et al. 2008).

Using the largest dataset analysed to date, CIMBA found results that were consistent with those of the BCLC for both BRCA1 and BRCA2 mutation carriers (Rebbeck et al. 2015). This study also identified multiple breast cancer cluster regions (BCCRs) in BRCA1 and BRCA2 and two further OCCRs in BRCA2. The analysis also showed that mutations conferring nonsense-mediated decay are associated with different breast and ovarian cancer risks. Although clear differences in risks were demonstrated by mutation location and function, it was not possible to estimate absolute risks of developing breast or ovarian cancer by mutation characteristics. To obtain valid absolute

Published by Bioscientifica Ltd. 
cancer risk estimates, it is necessary to perform studies which explicitly adjust for the ascertainment of mutation carriers on the basis of family history and which take into account the competing risks of breast and ovarian cancer and the population prevalence of specific mutations.

\section{Lifestyle/hormonal risk factors}

As explained previously, environmental/lifestyle factors may be important in explaining some of the variation in breast and ovarian cancer risk for BRCA1 and BRCA2 mutation carriers. The vast majority of data used to assess the associations has been retrospective and from selected individuals from multiple-case breast and ovarian cancer families. Moreover, different studies have used different methods to estimate the relative risks associated with potential risk factors, each with their strengths and weaknesses in terms of statistical power and adjustment for possible biases. Although prospective studies of mutation carriers unaffected at recruitment are optimal to overcome information, selection or ascertainment biases, they are faced with substantial challenges, including small sample sizes, limited prospective follow-up period (accrual of incident cases), gaps in the information available on risk factors between follow-ups, and loss to follow-up. The latter is further influenced by women undergoing prophylactic interventions (bilateral oophorectomy and/or bilateral mastectomy). Until findings from largescale prospective studies become available, we must assess the evidence from retrospective studies on its merits, to be able to inform mutation carriers, clinicians and genetic counsellors about individual cancer risk for mutation carriers and what can be done to reduce it.

Unfortunately, very few consistent findings have been reported across over 40 publications based on analyses of retrospective case-control data from mutation carriers (reviewed in (Friebel et al. 2014)). Most consistent across studies have been findings for tamoxifen use and reduced breast cancer risk for both BRCA1 and BRCA2 mutation carriers, with reported relative risk (RR) estimates ranging between 0.33 and 0.63 (Narod et al. 2000, Gronwald et al. 2006b, Phillips et al. 2013), and oral contraceptive use and protection from ovarian cancer risk for BRCA1 mutation carriers (RR estimates: 0.40-0.56) (Narod et al. 2001, Gronwald et al. 2006a, McLaughlin et al. 2007, Antoniou et al. 2009a). However, there was potential overlap in some of the data (Narod et al. 2000, 2001, Gronwald et al. 2006a,b, McLaughlin et al. 2007) and one study investigated only the association between tamoxifen and risk of contralateral breast cancer in affected women
(Phillips et al. 2013). Both these findings are consistent with the associations of these risk factors with cancer risks in the general population. The findings that exposure to chest X-rays at young ages is associated with an increased risk of breast cancer for mutation carriers were somewhat consistent (Andrieu et al. 2006, Lecarpentier et al. 2011, Pipje et al. 2012), although there was overlap between these studies and a subsequent smaller study found no evidence of association (John et al. 2013).

The reported findings for BRCA1 mutation carriers in relation to reproductive history and breast cancer risk have also been relatively consistent across studies. In line with the established associations for the general population, breast feeding for at least 1 year has been found to be protective (RR: 0.50-0.68) (Jernstrom et al. 2004, Andrieu et al. 2006, Gronwald et al. 2006a, Kotsopoulos et al. $2012 a, b$ ), as has later age at menarche (Chang-Claude et al. 2007, Kotsopoulos et al. 2005, 2012a), (RR: 0.91 per year; Kotsopoulos et al. 2012a). Later age at first fullterm pregnancy has also consistently been reported to be associated with reduced risk of breast cancer for BRCA1 mutation carriers (Andrieu et al. 2006, Antoniou et al. 2006, Milne et al. 2010b, Lecarpentier et al. 2012) (RR: 0.65 for age $\geq 30$ years vs $<30$ years; Friebel et al. 2014), which is in contrast to what is known about the association with risk for overall breast cancer in the general population. It is not clear why this would be the case, although there is evidence that the association in the general population differs by disease subtype and the protective effect of early childbirth is not observed for triple-negative breast cancer (Yang et al. 2011, Barnard et al. 2015), which comprises approximately two-thirds of all tumours diagnosed in BRCA1 mutation carriers (Mavaddat et al. 2012). Findings for these factors and breast cancer risk for BRCA2 mutation carriers have been null or inconclusive (Friebel et al. 2014). Observations from studies of parity and breast cancer risk have also been largely consistent for $B R C A 1$ and $B R C A 2$ mutation carriers, and the general population (Kelsey et al. 1993), with more full-term pregnancies associated with protection from breast cancer (Andrieu et al. 2006, Antoniou et al. 2006, Milne et al. 2010b, Lecarpentier et al. 2012) (RR: 0.83 per pregnancy, Friebel et al. 2014), although contradictory findings have also been published (Jernstrom et al. 1999, Cullinane et al. 2005, Kotsopoulos et al. 2012a).

Findings for BRCA1 mutation carriers in relation to oral contraceptive use and smoking have been inconsistent (Brunet et al. 1998, Narod et al. 2002, Ghadirian et al. 2004, Colilla et al. 2006, Haile et al. 2006, Brohet et al. 2007, Breast Cancer Family Registry 2008, Ginsburg et al. 2009, Bernholtz et al. 2011, Lecarpentier et al. 2011), even

Published by Bioscientifica Ltd 
within reports from the same research groups (Brunet et al. 1998, Narod et al. 2002, Ghadirian et al. 2004, Gronwald et al. 2006a, Ginsburg et al. 2009). For BRCA2 mutation carriers, published evidence is more consistent with oral contraceptive use being associated with an increased risk of breast cancer (Haile et al. 2006, Brohet et al. 2007, Bernholtz et al. 2011). There is insufficient published evidence on associations with breast cancer risk for other factors such as hormone therapy and with ovarian cancer risk in BRCA2 mutation carriers for lifestyle/hormonal factors in general, in the latter case, predominantly due to small sample sizes. There is similarly little or no evidence on the effects on cancer risk for mutation carriers associated with obesity, physical activity, alcohol consumption and diet, so that, as for smoking, general population recommendations for healthy living should apply.

The outline above highlights that, despite an accumulating body of research, we know relatively little about how lifestyle factors modify breast and ovarian cancer risk for a woman with a BRCA1 or BRCA2 mutation. This places limitations on both the degree to which we can individualise risk prediction for mutation carriers and the advice that can be given to mutation carriers about how they can modify their behaviour to reduce their risk. With the exception of age at first full-term pregnancy for BRCA1 mutation carriers, there is little evidence that the risk factors for mutation carriers differ from those in the general population. As in the general population, the benefits of oral contraceptive use in terms of reducing risk of ovarian cancer must be weighed against the potential harms in terms of breast cancer risk.

Another risk-reducing intervention that has been assessed in several studies is risk-reducing salpingooophorectomy (RRSO), which has benefits in terms of ovarian cancer prevention and has been reported to be associated with a reduction in breast cancer risk of approximately $50 \%$ for $B R C A 1$ and BRCA2 mutation carriers (Rebbeck et al. 1999, 2002, Eisen et al. 2005, Kramer et al. 2005, Domchek et al. 2006, Kauff et al. 2008, Domchek et al. 2010). However, a recent publication has highlighted that the observed protection may be overestimated due to several biases inherent in the design and analytical approaches of these observational studies (Heemskerk-Gerritsen et al. 2015b). Although still the subject of debate (Chai et al. 2015, Heemskerk-Gerritsen et al. 2015a), two analyses have now shown that after accounting analytically for these biases, in particular the exclusion of prevalent breast cancer cases from the analysis and the allocation of immortal person-time to the non-RRSO comparison group, no protective effect of
RSSO for breast cancer is observed (Heemskerk-Gerritsen et al. 2015b). It is important that this issue is resolved so that BRCA1 and BRCA2 mutation carriers contemplating RRSO are aware of both the impact of doing so on their risk of breast cancer and what other measures they might take to reduce that risk. On the other hand, a recent comprehensive review of the literature on the role of bilateral risk-reducing mastectomy (BRRM) has found consistent evidence in both retrospective and prospective studies that BRRM is associated with a $>90 \%$ reduction in breast cancer risk for women with BRCA1 or BRCA2 mutations (Hartmann \& Lindor 2016).

\section{Mammographic density}

Mammographic density is one of the strongest risk factors for breast cancer in the general population. A meta-analysis of published studies estimated that the risk for women with mammographic density $\geq 75 \%$ is 4.64 times greater than that for women with $<5 \%$ mammographic density (McCormack \& dos Santos Silva 2006). Data from population-based studies also suggest that mammographic density is a risk factor for both ER-positive and ER-negative breast cancer (Bertrand et al. 2013), although some studies found associations only with ER-positive disease. Only three studies have investigated the association between mammographic density and breast cancer risk for BRCA1 and BRCA2 mutation carriers (Mitchell et al. 2006, Passaperuma et al. 2010, Ramon et al. 2015). The two largest studies, both retrospective (Mitchell et al. 2006, Ramon et al. 2015) with sample sizes of 206 and 691 mutation carriers (including 96 and 248 affected women, respectively) found that mammographic density is an independent risk factor for breast cancer in both BRCA1 and BRCA2 mutation carriers with similar magnitudes of association to those observed in the general population (RR: 2.30 for density $\geq 50 \%$ vs $<50 \%)$. However, a nested case-control study of mutation carriers that included a much smaller number $(N=46)$ of cases, all incident (Passaperuma et al. 2010), found no evidence of association. Although the balance of evidence suggests that mammographic density is likely to also be a breast cancer risk factor for BRCA1 and BRCA2 mutation carriers, additional and larger studies are required to fully characterise the associations.

\section{Implications for risk prediction}

The genetic and lifestyle/hormonal modifiers of breast or ovarian cancer risk for BRCA1 and BRCA2 mutation

Published by Bioscientifica Ltd 
carriers described previously, with modest associated relative risks, are likely to be of limited utility individually in terms of cancer risk prediction. However, the relative risks associated with several common genetic variants and/or lifestyle/hormonal factors in combination are much larger. Further, because women with BRCA1 and $B R C A 2$ mutations are already at high risk of developing breast or ovarian cancer, the combined effects of SNPs and lifestyle/hormonal risk factors translate into large differences in the absolute risks of developing the diseases (Antoniou et al. 2008b, 2010a).

Analyses of data from the Breast Cancer Association Consortium have demonstrated that in the general population, the common breast cancer genetic susceptibility variants combine multiplicatively on the risk of developing breast cancer (Mavaddat et al. 2015); no evidence of interactions between SNPs has been observed (Milne et al. 2014b). In mutation carriers, a systematic assessment of the pairwise interactions between all SNPs that are known to modify cancer risks is currently ongoing. However, analyses based on smaller subsets of SNPs suggest no evidence of departure from the multiplicative model for the joint effects of SNPs (Antoniou et al. 2008b, $2010 a$ ), as observed in the general population. Given the observed differences between $B R C A 1$ and $B R C A 2$ mutation carriers in the association patterns of the common genetic variants with breast cancer risk and their consistency with associations with ER-negative and ER-positive disease, respectively, the most likely underlying model of genetic susceptibility to breast cancer is one where the associated effects of common susceptibility variants and of BRCA1 and BRCA2 mutations on breast cancer risk would be multiplicative, after taking into account tumour ER status (Kuchenbaecker et al. 2014).

This multiplicative model can be applied to identify groups of mutation carriers who are at substantially different levels of risk. For example, on the basis of 10 variants associated with breast cancer risk for BRCA1 mutation carriers, the lifetime risk of developing breast cancer for the $5 \%$ of $B R C A 1$ carriers at lowest risk is predicted to be $28-50 \%$, compared to $81-100 \%$ for the $5 \%$ at highest risk (Couch et al. 2013). Similarly, based on the distribution of seven common genetic variants found to modify ovarian cancer risk for mutation carriers, the $5 \%$ of BRCA1 mutation carriers at lowest risk will have a lifetime risk of developing ovarian cancer less than $30 \%$, whereas the $5 \%$ at highest risk will have a lifetime risk greater than $60 \%$ (Couch et al. 2013). These differences in cancer risks may have practical implications for the clinical management of mutation carriers, for example in deciding the timing of preventative interventions.

These predictions were based on a limited number of SNPs. Several more have since been shown to be associated with breast and ovarian cancer risk for mutation carriers. In addition, a much larger number of common genetic variants are now known to be associated with breast and ovarian cancer risk in the general population. Given the effect sizes associated with individual SNPs, the power to detect associations with each of these SNPs in mutation carriers is limited by the currently available sample sizes. However, greater statistical power can be achieved by investigating their combined effects, modelled as a polygenic risk score (PRS) based on associations observed in the general population (Mavaddat et al. 2015). These studies are currently underway within CIMBA. PRSs based on large numbers of SNPs are expected to result in even larger differences in the absolute cancer risks estimated for mutation carriers at the extremes of the combined SNP distributions, compared with the limited SNP profiles investigated so far.

Furthermore, integrating the effects of the common genetic variants with other lifestyle/hormonal risk factors, family history and mammographic density, may enable the identification of groups of BRCA1 and BRCA2 mutation carriers with sufficiently different cancer risks to enable more effective stratified clinical management, as recently demonstrated for the general population (Garcia-Closas et al. 2014). As described previously, the associations for several of the risk factors still remain to be clarified. However, as an illustration of the potential for cancer risk stratification for BRCA1 and BRCA2 mutation carriers, we provide projected breast cancer risks for BRCA2 mutation carriers assuming that all common genetic factors (including risk-modifying SNPs and the OCCR effect), lifestyle/hormonal factors and mammographic density act multiplicatively on the risk of developing breast cancer. We also assumed that these risk factors have similar distributions in mutation carriers to those observed for overall breast cancer risk in the general population, as described in Garcia-Closas and coworkers (2014). This seems a reasonable assumption based on the observed association patterns for BRCA2 mutation carriers described previously. Given the differences in the association patterns of the genetic (and other) risk factors between $B R C A 1$ and $B R C A 2$ mutation carriers, and the fact that the associations for $B R C A 1$ mutation carriers are more similar to the associations for ER-negative breast cancer in the general population, constructing an equivalent figure for BRCA1 mutation carriers would require data on the

Published by Bioscientifica Ltd 
joint risk factor distributions with respect to ER-negative breast cancer risk which are not currently available. Figure 1 shows the predicted 5 -year breast cancer risks for BRCA2 mutation carriers at the bottom percentiles of the combined risk factor distribution. These demonstrate large differences in the absolute risk of developing breast cancer, which may have implications for decisions about cancer prevention. For example, no established risk thresholds exist for recommending anti-oestrogens for primary breast cancer prevention in $B R C A 1$ and $B R C A 2$ mutation carriers. In the United States, the approved chemoprevention threshold for the general population is a 5 -year breast cancer risk of $1.7 \%$. On the basis of the average breast cancer risk for BRCA2 mutation carriers, this threshold would be reached at age 28 years. However, the assumptions for the combined effects of risk factors indicate that $5 \%$ of $B R C A 2$ carriers at the lowest risk would not reach that threshold until age 40 years (Fig. 1). Similarly, no accepted risk thresholds for risk-reducing mastectomy exist, but the benefit from, and acceptability of, this aggressive procedure would be limited for women in the lower risk categories. These findings demonstrate that by integrating the effects of genetic, lifestyle/hormonal and other risk factors we can identify mutation carriers at substantially different levels of risk, which will be informative in the genetic counselling process to allow female mutation carriers to make more informed choices about the type and timing of cancer control. However, these projected risks remain theoretical

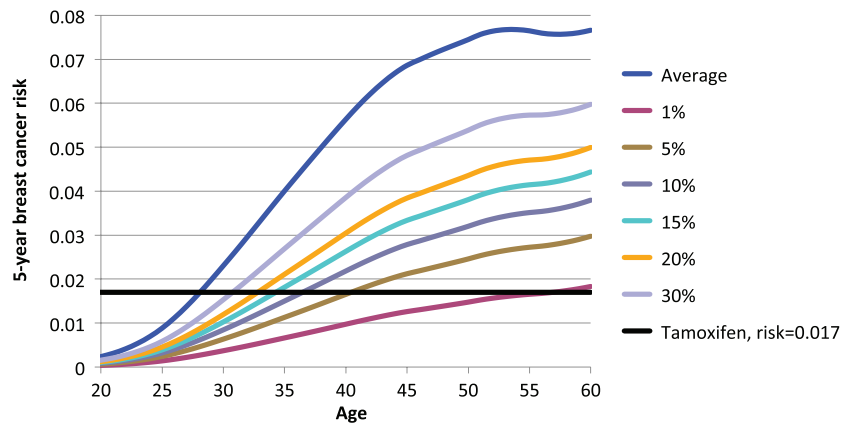

Figure 1

Predicted 5-year breast cancer risks for BRCA2 mutation carriers in the lower percentiles of the combined risk factor distribution. We assumed that all common genetic variants (including the OCCR effect), lifestyle/hormonal factors and mammographic density interact multiplicatively on the risk of developing breast cancer and that they have similar distributions to those observed in the general population, as described in Garcia-Closas et al. (2014). Absolute risks were calculated using the methods described in Antoniou et al. (2010a). The horizontal black line shows the absolute 5-year breast cancer risk at $1.7 \%$, which is the threshold applied in the United States for recommending anti-oestrogens for primary breast cancer prevention in the general population. at this point and the joint effects of all genetic, lifestyle/ hormonal and other risk factors will need to be evaluated in empirical studies. Further, the risk estimates will need to be validated in prospective cohorts of mutation carriers.

The clinical management of healthy women with BRCA1 and BRCA2 mutations often involves a combination of screening, prophylactic surgery and other risk-reduction strategies (Clark \& Domchek 2011). Prevention options include risk-reducing salpingooophorectomy (RRSO), risk-reducing mastectomy (RRM) and chemoprevention. However, these are invasive, have side effects and are associated with adverse psychosocial effects (recently reviewed in (Hartmann \& Lindor 2016)). Most women opt for RRSO, which results in premature menopause and is associated with adverse effects such as increased risks of cardiovascular disease and osteoporosis, as well as cognitive impairment and mortality from neurological diseases (Parker et al. 2009, Rivera et al. 2009a,b). Moreover, young mutation carriers make decisions about RRSO/RRM at a time in their lives that often coincides with family planning. The findings on genetic modifiers and calculations integrating their associated effects with other risk factors indicate that there is the potential to identify low- and moderate-risk groups of BRCA1 and BRCA2 mutation carriers, who will be appropriate for studies of less-intensive interventions such as salpingectomy (Falconer $e$ t al. 2015) and who may choose to avoid or delay preventive surgery.

\section{Unresolved issues in the identification and characterisation of risk-modifying factors}

Several important challenges remain in the identification of breast and ovarian risk-modifying factors for BRCA1 and BRCA2 mutation carriers. The first is sample size. Even for the study of common genetic modifiers, for which retrospective studies have proven to be adequate, combining data from $>35,000$ mutation carriers through the Consortium of Investigators of Modifiers of BRCA1/2 (CIMBA) (Chenevix-Trench et al. 2007), has proven to be insufficient to detect associations with individual genetic variants that have small effects on risk. Instead, studies of carriers now focus primarily on replicating associations observed in the general population and evaluating their combined effects (as polygenic risk scores) in risk prediction for these high-risk women. Much more of a challenge is the assessment of lifestyle/hormonal modifiers, for which study design is a far more important issue and less data have been collected. Although it is clear that prospective studies are required, sample size is

Published by Bioscientifica Ltd 
an even greater limitation for these, and even studies with extensive follow-up periods have substantial censoring due to women undergoing prophylactic interventions. Multi-consortium collaborations, such as that formed by the International BRCA1/2 Carrier Cohort Study (http://www.ibccs.nl/), the kConFab Clinical Follow-Up Study (Phillips et al. 2005) and the Breast Cancer Family Registries (http://epi.grants.cancer.gov/CFR/about_breast. html) will be essential to overcome these challenges.

Sample size impacts to an even greater extent on the estimation of combined effects of genetic and lifestyle factors on cancer risk for mutation carriers, even with the use of combined data through consortia. The general approach to work around this problem has been to assume that these factors act independently in modifying risk, unless evidence to the contrary is observed. Although statistical power to detect deviations from log-additive combined effects is limited, studies in the general population have consistently found very little evidence of these (Milne et al. 2010a,b, Travis et al. 2010, Campa et al. 2011, Nickels et al. 2013, Rudolph et al. 2015). Prospective studies will be essential to assess the validity of this assumption and of the risk prediction models more generally. Sample size similarly limits the capacity to identify interactions between BRCA1 and BRCA2 and other variants, particularly rare variants.

Future work will require several other issues to be addressed, including appropriate analytical consideration of the fact that BRCA1 and BRCA2 increase the risk of cancers other than breast and ovarian; risk prediction models are based primarily on data for mutation carriers that present at family cancer clinics and may be less relevant to those identified through primary care or population screening; the development of risk prediction tools that are easy to use and to understand; and cancer risk modifiers and risk prediction for male mutation carriers. Although multiple common genetic modifiers of breast or ovarian cancer risks for BRCA1 and BRCA2 mutation carriers have been identified, relatively few of these have been subjected to fine-scale mapping studies to fully characterise the associations with all the genetic variants at those regions and to identify plausible candidate causal variants. It will be important to carry out these studies because they will inform downstream functional studies to better understand the biological basis of cancer risk modification. They may also lead to the discovery of novel therapeutic targets for mutation carriers.

The vast majority of the studies on risk-modifying factors for BRCA1 and BRCA2 mutation carriers have focused on women of European ancestry from Western populations. The findings therefore may not be applicable to populations from other countries with different breast and ovarian cancer incidence patterns and different risk factor distributions or to mutation carriers from ethnic minorities in Western countries. There are a number of ongoing efforts at the moment to pool data from other populations (e.g. in Asian countries (Kwong et al. 2016, Nakamura et al. 2016)), but further large-scale studies are required in such populations to comprehensively assess the effects of genetic risk-modifying factors for women with BRCA1 and BRCA2 mutations.

\section{Strategies for implementation in clinical practice}

Given the large differences in absolute risks by the combined distribution of genetic, lifestyle/hormonal and risk factors for mutation carriers, women with BRCA1 and BRCA2 mutations could be one of the first groups to benefit from clinical applications of findings from GWAS and epidemiological studies. However, parallel to the analytical and methodological work required to develop cancer risk prediction models and risk assessment tools specifically for BRCA1 and BRCA2 mutation carriers, clinical implementation studies will also be required before personalised risk prediction can be provided to mutation carriers on routine basis. It will be necessary to perform risk communication and acceptability studies to assess the attitudes of women with BRCA1 and BRCA2 mutations to risk stratification and to breast and ovarian cancer riskstratified management. It will also be essential to assess the attitudes of health care professionals to providing personalised cancer risk estimates. The provision of more personalised risk predictions on the basis of polygenic risk scores or comprehensive risk prediction models will require feasibility studies to be performed to assess the uptake of personalised cancer risk prediction and the uptake of the different risk management options (screening/risk-reducing surgery/chemoprevention), as well as the psychosocial impact and cost-effectiveness of these. It will also be necessary to educate health care providers in the provision of personalised cancer risk predictions for mutation carriers on the basis of factors modifying risks.

We have come a long way in understanding and more precisely estimating the average breast and ovarian cancer risks for $B R C A 1$ and $B R C A 2$ mutation carriers. Large-scale consortia have led international collaboration, harnessing advances in genotyping technologies, to identify many common genetic factors that modify these risks, and

Published by Bioscientifica Ltd. 
polygenic risk scores based on these show great promise in affording more personalised genetic counselling and cancer prevention based on stratified risk prediction. Further work is required to establish the relative risks for mutation carriers associated with lifestyle/hormonal and other risk factors and to incorporate these into risk prediction models to achieve even greater precision. Multidisciplinary collaboration is required to overcome the various challenges inherent to this important and potentially transformative work.

\section{Declaration of interest}

The authors declare that there is no conflict of interest that could be perceived as prejudicing the impartiality of this review.

\section{Funding}

A C A is a Cancer Research - UK Senior Research Fellow. This work is supported by Cancer Research - UK grants C12292/A20861 and C12292/A11174.

\section{References}

Ahmed S, Thomas G, Ghoussaini M, Healey CS, Humphreys MK, Platte R, Morrison J, Maranian M, Pooley KA, Luben R, et al. 2009 Newly discovered breast cancer susceptibility loci on 3p24 and 17q23.2. Nature Genetics 41 585-590. (doi:10.1038/ng.354)

Alsop K, Fereday S, Meldrum C, deFazio A, Emmanuel C, George J, Dobrovic A, Birrer MJ, Webb PM, Stewart C, et al. 2012 BRCA mutation frequency and patterns of treatment response in BRCA mutation-positive women with ovarian cancer: a report from the Australian Ovarian Cancer Study Group. Journal of Clinical Oncology 30 2654-2663. (doi:10.1200/JCO.2011.39.8545)

Andrieu N, Goldgar DE, Easton DF, Rookus MA, Brohet R, Antoniou AC, Peack S, Evans DG, Eccles D, Douglas F, et al. 2006 Pregnancies, breastfeeding and breast cancer risk in the Internatioinal BRCA1/2 carrier Cohort Study (IBCCS). Journal of National Cancer Institute $\mathbf{9 8}$ 535-544. (doi:10.1093/jnci/djj132)

Anglian Breast Cancer Study Group 2000 Prevalence and penetrance of BRCA1 and BRCA2 mutations in a population-based series of breast cancer cases. British Journal of Cancer 83 1301-1308. (doi:10.1054/ bjoc.2000.1407)

Antoniou A, Pharoah PD, Narod S, Risch HA, Eyfjord JE, Hopper JL, Loman N, Olsson H, Johannsson O, Borg A, et al. 2003 Average risks of breast and ovarian cancer associated with BRCA1 or BRCA2 mutations detected in case Series unselected for family history: a combined analysis of 22 studies. American Journal of Human Genetics 72 1117-1130. (doi:10.1086/375033)

Antoniou AC, Goldgar DE, Andrieu N, Chang-Claude J, Brohet R, Rookus MA \& Easton DF 2005a A weighted cohort approach for analysing factors modifying disease risks in carriers of high-risk susceptibility genes. Genetic Epidemiology 29 1-11. (doi:10.1002/ gepi.20074)

Antoniou AC, Pharoah PD, Narod S, Risch HA, Eyfjord JE, Hopper JL, Olsson H, Johannsson O, Borg A, Pasini B, et al. 2005b Breast and ovarian cancer risks to carriers of the BRCA1 5382insC and 185delAG and BRCA2 6174delT mutations: a combined analysis of 22 population based studies. Journal of Medical Genetics 42 602-603. (doi:10.1136/jmg.2004.024133)
Antoniou AC, Shenton A, Maher ER, Watson E, Woodward E, Lalloo F, Easton DF \& Evans DG 2006 Parity and breast cancer risk among BRCA1 and BRCA2 mutation carriers. Breast Cancer Research 8 R72. (doi:10.1186/bcr1630)

Antoniou AC, Cunningham AP, Peto J, Evans DG, Lalloo F, Narod SA, Risch HA, Eyfjord JE, Hopper JL, Southey MC, et al. 2008a The BOADICEA model of genetic susceptibility to breast and ovarian cancers: updates and extensions. British Journal of Cancer 98 1457-1466. (doi:10.1038/sj.bjc.6604305)

Antoniou AC, Spurdle AB, Sinilnikova OM, Healey S, Pooley KA, Schmutzler RK, Versmold B, Engel C, Meindl A, Arnold N, et al. $2008 b$ Common breast cancer-predisposition alleles are associated with breast cancer risk in BRCA1 and BRCA2 mutation carriers. American Journal of Human Genetics 82 937-948. (doi:10.1016/ j.ajhg.2008.02.008)

Antoniou AC, Rookus M, Andrieu N, Brohet R, Chang-Claude J, Peock S, Cook M, Evans DG, Eeles R, Nogues C, et al. 2009a Reproductive and hormonal factors, and ovarian cancer risk for BRCA1 and BRCA2 mutation carriers: results from the International BRCA1/2 Carrier Cohort Study. Cancer Epidemiology, Biomarkers \& Prevention 18 601-610. (doi:10.1158/1055-9965.epi-08-0546)

Antoniou AC, Sinilnikova OM, McGuffog L, Healey S, Nevanlinna H, Heikkinen T, Simard J, Spurdle AB, Beesley J, Chen X, et al. $2009 b$ Common variants in LSP1, 2q35 and 8q24 and breast cancer risk for BRCA1 and BRCA2 mutation carriers. Human Molecular Genetics 18 4442-4456. (doi:10.1093/hmg/ddp372)

Antoniou AC, Beesley J, McGuffog L, Sinilnikova OM, Healey S, Neuhausen SL, Ding YC, Rebbeck TR, Weitzel JN, Lynch HT, et al. $2010 a$ Common breast cancer susceptibility alleles and the risk of breast cancer for BRCA1 and BRCA2 mutation carriers: implications for risk prediction. Cancer Research 70 9742-9754. (doi:10.1158/00085472.CAN-10-1907)

Antoniou AC, Wang X, Fredericksen ZS, McGuffog L, Tarrell R, Sinilnikova OM, Healey S, Morrison J, Kartsonaki C, Lesnick T, et al. $2010 b$ A locus on 19p13 modifies risk of breast cancer in BRCA1 mutation carriers and is associated with hormone receptor-negative breast cancer in the general population. Nature Genetics 42 885-892. (doi:10.1038/ng.669)

Antoniou AC, Kartsonaki C, Sinilnikova OM, Soucy P, McGuffog L, Healey S, Lee A, Peterlongo P, Manoukian S, Peissel B, et al. 2011 Common alleles at 6q25.1 and 1p11.2 are associated with breast cancer risk for BRCA1 and BRCA2 mutation carriers. Human Molecular Genetics 20 3304-3321. (doi:10.1093/hmg/ ddr226)

Antoniou AC, Kuchenbaecker KB, Soucy P, Beesley J, Chen X, McGuffog L, Lee A, Barrowdale D, Healey S, Sinilnikova OM, et al. 2012 Common variants at 12p11, 12q24, 9p21, 9q31.2 and in ZNF365 are associated with breast cancer risk for BRCA1 and/or BRCA2 mutation carriers. Breast Cancer Research 14 R33. (doi:10.1186/bcr3121)

Auton A, Brooks LD, Durbin RM, Garrison EP, Kang HM, Korbel JO, Marchini JL, McCarthy S, McVean GA \& Abecasis GR 2015 A global reference for human genetic variation. Nature 526 68-74. (doi:10.1038/nature15393)

Barnard ME, Boeke CE \& Tamimi RM 2015 Established breast cancer risk factors and risk of intrinsic tumor subtypes. Biochimica et Biophysica Acta 1856 73-85. (doi:10.1016/j.bbcan.2015.06.002)

Barnes DR, Lee A, Easton DF \& Antoniou AC 2012 Evaluation of association methods for analysing modifiers of disease risk in carriers of high-risk mutations. Genetic Epidemiology 36 274-291. (doi:10.1002/gepi.21620)

Begg CB, Haile RW, Borg A, Malone KE, Concannon P, Thomas DC, Langholz B, Bernstein L, Olsen JH, Lynch CF, et al. 2008 Variation of breast cancer risk among BRCA1/2 carriers. JAMA 299 194-201.

Bernholtz S, Laitman Y, Kaufman B, Paluch SS \& Friedman E 2011 Cancer risk in Jewish BRCA1 and BRCA2 mutation carriers: effects of oral 
contraceptive use and parental origin of mutation. Breast Cancer Research and Treatment 129 557-563. (doi:10.1007/s10549-011-1509-z)

Bertrand KA, Tamimi RM, Scott CG, Jensen MR, Pankratz V, Visscher D, Norman A, Couch F, Shepherd J, Fan B, et al. 2013 Mammographic density and risk of breast cancer by age and tumor characteristics. Breast Cancer Research 15 R104. (doi:10.1186/bcr3570)

Bojesen SE, Pooley KA, Johnatty SE, Beesley J, Michailidou K, Tyrer JP, Edwards SL, Pickett HA, Shen HC, Smart CE, et al. 2013 Multiple independent variants at the TERT locus are associated with telomere length and risks of breast and ovarian cancer. Nature Genetics $\mathbf{4 5}$ 371-384, 384e371-372. (doi:10.1038/ng.2566)

Bolton KL, Tyrer J, Song H, Ramus SJ, Notaridou M, Jones C, Sher T, Gentry-Maharaj A, Wozniak E, Tsai YY, et al. 2010 Common variants at 19 p13 are associated with susceptibility to ovarian cancer. Nature Genetics 42 880-884. (doi:10.1038/ng.666)

Breast Cancer Association Consortium 2006 Commonly studied singlenucleotide polymorphisms and breast cancer: results from the Breast Cancer Association Consortium. Journal of National Cancer Institute 98 1382-1396. (doi:10.1093/jnci/djj374)

Breast Cancer Family Registry 2008 Smoking and risk of breast cancer in carriers of mutations in BRCA1 or BRCA2 aged less than 50 years. Breast Cancer Research and Treatment 109 67-75. (doi:10.1007/s10549-007-9621-9)

Brohet RM, Goldgar DE, Easton DF, Antoniou AC, Andrieu N, Chang-Claude J, Peock S, Eeles RA, Cook M, Chu C, et al. 2007 Oral contraceptives and breast cancer risk in the international BRCA1/2 carrier cohort study: a report from EMBRACE, GENEPSO, GEO-HEBON, and the IBCCS Collaborating Group. Journal of Clinical Oncology 25 3831-3836. (doi:10.1200/JCO.2007.11.1179)

Brohet RM, Velthuizen ME, Hogervorst FB, Ej Meijers-Heijboer H, Seynaeve C, Collee MJ, Verhoef S, Ausems MG, Hoogerbrugge N, van Asperen CJ, et al. 2014 Breast and ovarian cancer risks in a large series of clinically ascertained families with a high proportion of BRCA1 and BRCA2 Dutch founder mutations. Journal of Medical Genetics 51 98-107. (doi:10.1136/jmedgenet-2013-101974)

Brunet JS, Ghadirian P, Rebbeck TR, Lerman C, Garber JE, Tonin PN, Abrahamson J, Foulkes WD, Daly M, Wagner-Costalas J, et al. 1998 Effect of smoking on breast cancer in carriers of mutant BRCA1 or BRCA2 genes. Journal of National Cancer Institute 90 761-766. (doi:10.1093/jnci/90.10.761)

Cai Q, Long J, Lu W, Qu S, Wen W, Kang D, Lee JY, Chen K, Shen H, Shen CY, et al. 2011 Genome-wide association study identifies breast cancer risk variant at 10q21.2: results from the Asia Breast Cancer Consortium. Human Molecular Genetics 20 4991-4999. (doi:10.1093/ $\mathrm{hmg} / \mathrm{ddr} 405$ )

Cai Q, Zhang B, Sung H, Low SK, Kweon SS, Lu W, Shi J, Long J, Wen W, Choi JY, et al. 2014 Genome-wide association analysis in East Asians identifies breast cancer susceptibility loci at 1q32.1, 5q14.3 and 15q26.1. Nature Genetics 46 886-890. (doi:10.1038/ng.3041)

Campa D, Kaaks R, Le Marchand L, Haiman CA, Travis RC, Berg CD, Buring JE, Chanock SJ, Diver WR, Dostal L, et al. 2011 Interactions between genetic variants and breast cancer risk factors in the breast and prostate cancer cohort consortium. Journal of National Cancer Institute 103 1252-1263. (doi:10.1093/jnci/djr265)

Chai X, Domchek S, Kauff N, Rebbeck T \& Chen J 2015 RE: breast cancer risk after salpingo-oophorectomy in healthy BRCA1/2 mutation carriers: revisiting the evidence for risk reduction. Journal of National Cancer Institute 107. (doi:10.1093/jnci/djv033)

Chang-Claude J, Andrieu N, Rookus M, Brohet R, Antoniou AC, Peock S, Davidson R, Izatt L, Cole T, Nogues C, et al. 2007 Age at menarche and menopause and breast cancer risk in the International BRCA1/2 Carrier Cohort Study. Cancer Epidemiology, Biomarkers \& Prevention 16 740-746. (doi:10.1158/1055-9965.epi-06-0829)

Chen S, Iversen ES, Friebel T, Finkelstein D, Weber BL, Eisen A Peterson LE, Schildkraut JM, Isaacs C, Peshkin BN, et al. 2006
Characterization of BRCA1 and BRCA2 mutations in a large United States sample. Journal of Clinical Oncology 24 863-871. (doi:10.1200/JCO.2005.03.6772)

Chenevix-Trench G, Milne RL, Antoniou AC, Couch FJ, Easton DF, Goldgar DE \& Cimba 2007 An international initiative to identify genetic modifiers of cancer risk in BRCA1 and BRCA2 mutation carriers: the Consortium of Investigators of Modifiers of BRCA1 and BRCA2 (CIMBA). Breast Cancer Research 9104 (doi:10.1186/bcr1670)

Clark AS \& Domchek SM 2011 Clinical management of hereditary breast cancer syndromes. Journal of Mammary Gland Biology and Neoplasia 16 17-25. (doi:10.1007/s10911-011-9200-x)

Colilla S, Kantoff PW, Neuhausen SL, Godwin AK, Daly MB, Narod SA, Garber JE, Lynch HT, Brown M, Weber BL, et al. 2006 The joint effect of smoking and AIB1 on breast cancer risk in BRCA1 mutation carriers. Carcinogenesis 27 599-605. (doi:10.1093/carcin/bgi246)

Couch FJ, Gaudet MM, Antoniou AC, Ramus SJ, Kuchenbaecker KB, Soucy P, Beesley J, Chen X, Wang X, Kirchhoff T, et al. 2012 Common variants at the 19p13.1 and ZNF365 loci are associated with ER subtypes of breast cancer and ovarian cancer risk in BRCA1 and BRCA2 mutation carriers. Cancer Epidemiology, Biomarkers \& Prevention 21 645-657. (doi:10.1158/1055-9965.epi-11-0888)

Couch FJ, Wang X, McGuffog L, Lee A, Olswold C, Kuchenbaecker KB, Soucy P, Fredericksen Z, Barrowdale D, Dennis J, et al. 2013 Genome-wide association study in BRCA1 mutation carriers identifies novel loci associated with breast and ovarian cancer risk. PLoS Genetics 9 e1003212. (doi:10.1371/journal.pgen.1003212)

Couch FJ, Kuchenbaecker KB, Michailidou K, Mendoza-Fandino GA, Nord S, Lilyquist J, Olswold C, Hallberg E, Agata S, Ahsan H, et al. 2016 Identification of four novel susceptibility loci for estrogen receptor negative breast cancer. Nature Communications 711375 (doi:10.1038/ncomms11375)

Cox A, Dunning AM, Garcia-Closas M, Balasubramanian S, Reed MW, Pooley KA, Scollen S, Baynes C, Ponder BA, Chanock S, et al. 2007 A common coding variant in CASP8 is associated with breast cancer risk. Nature Genetics 39 352-358. (doi:10.1038/ng1981)

Cullinane CA, Lubinski J, Neuhausen SL, Ghadirian P, Lynch HT, Isaacs C, Weber B, Moller P, Offit K, Kim-Sing C, et al. 2005 Effect of pregnancy as a risk factor for breast cancer in BRCA1/BRCA2 mutation carriers. International Journal of Cancer 117 988-991. (doi:10.1002/ijc.21273)

Domchek SM, Friebel TM, Neuhausen SL, Wagner T, Evans G, Isaacs C, Garber JE, Daly MB, Eeles R, Matloff E, et al. 2006 Mortality after bilateral salpingo-oophorectomy in BRCA1 and BRCA2 mutation carriers: a prospective cohort study. Lancet Oncology 7 223-229. (doi:10.1016/S1470-2045(06)70585-X)

Domchek SM, Friebel TM, Singer CF, Evans DG, Lynch HT, Isaacs C, Garber JE, Neuhausen SL, Matloff E, Eeles R, et al. 2010 Association of risk-reducing surgery in BRCA1 or BRCA2 mutation carriers with cancer risk and mortality. JAMA 304 967-975. (doi:10.1001/ jama.2010.1237)

Dunning AM, Michailidou K, Kuchenbaecker KB, Thompson D, French JD, Beesley J, Healey CS, Kar S, Pooley KA, Lopez-Knowles E, et al. 2016 Breast cancer risk variants at 6q25 display different phenotype associations and regulate ESR1, RMND1 and CCDC170. Nature Genetics 48 374-386. (doi:10.1038/ng.3521)

Easton DF, Ford D \& Bishop DT 1995 Breast and ovarian cancer incidence in BRCA1-mutation carriers. Breast Cancer Linkage Consortium. American Journal of Human Genetics 56 265-271.

Easton DF, Pooley KA, Dunning AM, Pharoah PD, Thompson D, Ballinger DG, Struewing JP, Morrison J, Field H, Luben R, et al. 2007 Genome-wide association study identifies novel breast cancer susceptibility loci. Nature 447 1087-1093. (doi:10.1038/ nature05887

Eisen A, Lubinski J, Klijn J, Moller P, Lynch HT, Offit K, Weber B, Rebbeck T, Neuhausen SL, Ghadirian P, et al. 2005 Breast cancer risk

Published by Bioscientifica Ltd. 
following bilateral oophorectomy in BRCA1 and BRCA2 mutation carriers: an international case-control study. Journal of Clinical Oncology 23 7491-7496. (doi:10.1200/JCO.2004.00.7138)

Evans DG, Harkness E, Lalloo F \& Howell A 2014 Long-term prospective clinical follow-up after BRCA1/2 presymptomatic testing: BRCA2 risks higher than in adjusted retrospective studies. Journal of Medical Genetics 51 573-580. (doi:10.1136/jmedgenet-2014-102336)

Falconer H, Yin L, Gronberg H \& Altman D 2015 Ovarian cancer risk after salpingectomy: a nationwide population-based study. Journal of National Cancer Institute 107. (doi:10.1093/jnci/dju410)

Fletcher O, Johnson N, Orr N, Hosking FJ, Gibson LJ, Walker K, Zelenika D, Gut I, Heath S, Palles C, et al. 2011 Novel breast cancer susceptibility locus at 9q31.2: results of a genome-wide association study. Journal of National Cancer Institute 103 425-435. (doi:10.1093/jnci/djq563)

Ford D, Easton DF, Stratton M, Narod S, Goldgar D, Devilee P, Bishop DT, Weber B, Lenoir G, Chang-Claude J, et al. 1998 Genetic heterogeneity and penetrance analysis of the BRCA1 and BRCA2 genes in breast cancer families. The Breast Cancer Linkage Consortium. American Journal of Human Genetics 62 676-689. (doi:10.1086/301749)

French JD, Ghoussaini M, Edwards SL, Meyer KB, Michailidou K, Ahmed S, Khan S, Maranian MJ, O'Reilly M, Hillman KM, et al. 2013 Functional variants at the 11q13 risk locus for breast cancer regulate cyclin D1 expression through long-range enhancers. American Journal of Human Genetics 92 489-503. (doi:10.1016/ j.ajhg.2013.01.002)

Friebel TM, Domchek SM \& Rebbeck TR 2014 Modifiers of cancer risk in BRCA1 and BRCA2 mutation carriers: systematic review and meta-analysis. Journal of National Cancer Institute 106 dju091. (doi:10.1093/jnci/dju091)

Gabai-Kapara E, Lahad A, Kaufman B, Friedman E, Segev S, Renbaum P, Beeri R, Gal M, Grinshpun-Cohen J, Djemal K, et al. 2014 Population-based screening for breast and ovarian cancer risk due to BRCA1 and BRCA2. PNAS 111 14205-14210. (doi:10.1073/pnas.1415979111)

Garcia-Closas M, Couch FJ, Lindstrom S, Michailidou K, Schmidt MK, Brook MN, Orr N, Rhie SK, Riboli E, Feigelson HS, et al. 2013 Genome-wide association studies identify four ER negative-specific breast cancer risk loci. Nature Genetics 45 392-398, 398e391-392. (doi:10.1038/ng.2561)

Garcia-Closas M, Gunsoy NB \& Chatterjee N 2014 Combined associations of genetic and environmental risk factors: implications for prevention of breast cancer. Journal of National Cancer Institute 106. (doi:10.1093/jnci/djv127)

Gaudet MM, Kuchenbaecker KB, Vijai J, Klein RJ, Kirchhoff T, McGuffog L, Barrowdale D, Dunning AM, Lee A, Dennis J, et al. 2013 Identification of a BRCA2-specific modifier locus at 6p24 related to breast cancer risk. PLoS Genetics 9 e1003173. (doi:10.1371/journal.pgen.1003173)

Gayther SA, Warren W, Mazoyer S, Russell PA, Harrington PA, Chiano M, Seal S, Hamoudi R, van Rensburg EJ, Dunning AM, et al. 1995 Germline mutations of the BRCA1 gene in breast and ovarian cancer families provide evidence for a genotype-phenotype correlation. Nature Genetics 11 428-433. (doi:10.1038/ng1295-428)

Gayther SA, Mangion J, Russell P, Seal S, Barfoot R, Ponder BA, Stratton MR \& Easton D 1997 Variation of risks of breast and ovarian cancer associated with different germline mutations of the BRCA2 gene. Nature Genetics 15 103-105. (doi:10.1038/ ng0197-103)

Ghadirian P, Lubinski J, Lynch H, Neuhausen SL, Weber B, Isaacs C, Baruch RG, Randall S, Ainsworth P, Friedman E, et al. 2004 Smoking and the risk of breast cancer among carriers of BRCA mutations. International Journal of Cancer 110 413-416. (doi:10.1002/ijc.20106)

Ghoussaini M, Fletcher O, Michailidou K, Turnbull C, Schmidt MK, Dicks E, Dennis J, Wang Q, Humphreys MK, Luccarini C, et al.
2012 Genome-wide association analysis identifies three new breast cancer susceptibility loci. Nature Genetics 44 312-318. (doi:10.1038/ ng.1049)

Ginsburg O, Ghadirian P, Lubinski J, Cybulski C, Lynch H, Neuhausen S, Kim-Sing C, Robson M, Domchek S, Isaacs C, et al. 2009 Smoking and the risk of breast cancer in BRCA1 and BRCA2 carriers: an update. Breast Cancer Research and Treatment 114 127-135. (doi:10.1007/s10549-008-9977-5)

Goode EL, Chenevix-Trench G, Song H, Ramus SJ, Notaridou M, Lawrenson K, Widschwendter M, Vierkant RA, Larson MC, Kjaer SK, et al. 2010 A genome-wide association study identifies susceptibility loci for ovarian cancer at 2q31 and 8q24. Nature Genetics 42 874-879. (doi:10.1038/ng.668)

Gronwald J, Byrski T, Huzarski T, Cybulski C, Sun P, Tulman A, Narod SA \& Lubinski J $2006 a$ Influence of selected lifestyle factors on breast and ovarian cancer risk in BRCA1 mutation carriers from Poland. Breast Cancer Research and Treatment 95 105-109. (doi:10.1007/s10549-005-9051-5)

Gronwald J, Tung N, Foulkes WD, Offit K, Gershoni R, Daly M, Kim-Sing C, Olsson H, Ainsworth P, Eisen A, et al. 2006b Tamoxifen and contralateral breast cancer in BRCA1 and BRCA2 carriers: an update. International Journal of Cancer 118 2281-2284. (doi:10.1002/ijc.21536)

Haile RW, Thomas DC, McGuire V, Felberg A, John EM, Milne RL, Hopper JL, Jenkins MA, Levine AJ, Daly MM, et al. 2006 BRCA1 and BRCA2 mutation carriers, oral contraceptive use, and breast cancer before age 50. Cancer Epidemiology Biomarkers \& Prevention 15 1863-1870. (doi:10.1158/1055-9965.epi-06-0258)

Haiman CA, Chen GK, Vachon CM, Canzian F, Dunning A, Millikan RC, Wang X, Ademuyiwa F, Ahmed S, Ambrosone CB, et al. 2011 A common variant at the TERT-CLPTM1L locus is associated with estrogen receptor-negative breast cancer. Nature Genetics 43 1210-1214. (doi:10.1038/ng.985)

Hartmann LC \& Lindor NM 2016 The role of risk-reducing surgery in hereditary breast and ovarian cancer. New England Journal of Medicine 374 454-468. (doi:10.1056/NEJMra1503523)

Heemskerk-Gerritsen BA, Hooning MJ \& Rookus MA 2015a Response. Journal of National Cancer Institute $\mathbf{1 0 7}$

Heemskerk-Gerritsen BA, Seynaeve C, van Asperen CJ, Ausems MG, Collee JM, van Doorn HC, Gomez Garcia EB, Kets CM, van Leeuwen FE, Meijers-Heijboer HE, et al. 2015b Breast cancer risk after salpingo-oophorectomy in healthy BRCA1/2 mutation carriers: revisiting the evidence for risk reduction. Journal of National Cancer Institute 107. (doi:10.1093/jnci/djv033)

Hein R, Maranian M, Hopper JL, Kapuscinski MK, Southey MC, Park DJ, Schmidt MK, Broeks A, Hogervorst FB, Bueno-de-Mesquita HB, et al. 2012 Comparison of 6q25 breast cancer hits from Asian and European Genome Wide Association Studies in the Breast Cancer Association Consortium (BCAC). PLoS ONE 7 e42380. (doi:10.1371/journal.pone.0042380)

Hopper JL, Southey MC, Dite GS, Jolley DJ, Giles GG, McCredie MR, Easton DF \& Venter DJ 1999 Population-based estimate of the average age-specific cumulative risk of breast cancer for a defined set of protein-truncating mutations in BRCA1 and BRCA2. Australian Breast Cancer Family Study. Cancer Epidemiology Biomarkers \& Prevention 8 741-747.

Hunter DJ, Kraft P, Jacobs KB, Cox DG, Yeager M, Hankinson SE, Wacholder S, Wang Z, Welch R, Hutchinson A, et al. 2007 A genome-wide association study identifies alleles in FGFR2 associated with risk of sporadic postmenopausal breast cancer. Nature Genetics 39 870-874. (doi:10.1038/ng2075)

Jernstrom H, Lerman C, Ghadirian P, Lynch HT, Weber B, Garber J, Daly M, Olopade OI, Foulkes WD, Warner E, et al. 1999 Pregnancy and risk of early breast cancer in carriers of BRCA1 and BRCA2. Lancet 354 1846-1850. (doi:10.1016/S01406736(99)04336-6)
(C) 2016 Society for Endocrinology Printed in Great Britain 
Jernstrom H, Lubinski J, Lynch HT, Ghadirian P, Neuhausen S, Isaacs C, Weber BL, Horsman D, Rosen B, Foulkes WD, et al. 2004 Breast-feeding and the risk of breast cancer in BRCA1 and BRCA2 mutation carriers. Journal of National Cancer Institute 96 1094-1098. (doi:10.1093/jnci/djh211)

Jervis S, Song H, Lee A, Dicks E, Tyrer J, Harrington P, Easton DF Jacobs IJ, Pharoah PP \& Antoniou AC 2014 Ovarian cancer familial relative risks by tumour subtypes and by known ovarian cancer genetic susceptibility variants. Journal of Medical Genetics $\mathbf{5 1}$ 108-113. (doi:10.1136/jmedgenet-2013-102015)

Karlan BY, Berchuck A \& Mutch D 2007 The role of genetic testing for cancer susceptibility in gynecologic practice. Obstetrics \& Gynecology 110 155-167. (doi:10.1097/01.aog.0000269050.79143.84)

Kauff ND, Domchek SM, Friebel TM, Robson ME, Lee J, Garber JE, Isaacs C, Evans DG, Lynch H, Eeles RA, et al. 2008 Risk-reducing salpingo-oophorectomy for the prevention of BRCA1- and BRCA2associated breast and gynecologic cancer: a multicenter, prospective study. Journal of Clinical Oncology 26 1331-1337. (doi:10.1200/ JCO.2007.13.9626)

Kelsey JL, Gammon MD \& John EM 1993 Reproductive factors and breast cancer. Epidemiology Review 15 36-47.

Kotsopoulos J, Lubinski J, Lynch HT, Neuhausen SL, Ghadirian P, Isaacs C, Weber B, Kim-Sing C, Foulkes WD, Gershoni-Baruch R, et al. 2005 Age at menarche and the risk of breast cancer in BRCA1 and BRCA2 mutation carriers. Cancer Causes Control 16 667-674. (doi:10.1007/s10552-005-1724-1)

Kotsopoulos J, Lubinski J, Lynch HT, Kim-Sing C, Neuhausen S, Demsky R, Foulkes WD, Ghadirian P, Tung N, Ainsworth P, et al. $2012 a$ Oophorectomy after menopause and the risk of breast cancer in BRCA1 and BRCA2 mutation carriers. Cancer Epidemiology Biomarkers \& Prevention 21 1089-1096. (doi:10.1158/1055-9965.epi12-0201)

Kotsopoulos J, Lubinski J, Salmena L, Lynch HT, Kim-Sing C, Foulkes WD, Ghadirian P, Neuhausen SL, Demsky R, Tung N, et al. $2012 b$ Breastfeeding and the risk of breast cancer in BRCA1 and BRCA2 mutation carriers. Breast Cancer Research 14 R42. (doi:10.1186/bcr3138)

Kramer JL, Velazquez IA, Chen BE, Rosenberg PS, Struewing JP \& Greene MH 2005 Prophylactic oophorectomy reduces breast cancer penetrance during prospective, long-term follow-up of BRCA1 mutation carriers. Journal of Clinical Oncology 23 8629-8635. (doi:10.1200/JCO.2005.02.9199)

Kuchenbaecker K, Neuhausen S, Robson M, Barrowdale D, McGuffog L, Mulligan A, Andrulis I, Spurdle A, Schmidt M, Schmutzler R, et al. 2014 Associations of common breast cancer susceptibility alleles with risk of breast cancer subtypes in BRCA1 and BRCA2 mutation carriers. Breast Cancer Research 16 3416. (doi:10.1186/s13058-0140492-9)

Kuchenbaecker KB, Ramus SJ, Tyrer J, Lee A, Shen HC, Beesley J, Lawrenson K, McGuffog L, Healey S, Lee JM, et al. 2015 Identification of six new susceptibility loci for invasive epithelial ovarian cancer. Nature Genetics 47 164-171. (doi:10.1038/ng.3185)

Kwong A, Shin VY, Ho JC, Kang E, Nakamura S, Teo SH, Lee AS, Sng JH, Ginsburg OM, Kurian AW, et al. 2016 Comprehensive spectrum of BRCA1 and BRCA2 deleterious mutations in breast cancer in Asian countries. Journal of Medical Genetics 53 15-23. (doi:10.1136/ jmedgenet-2015-103132)

Lawrenson K, Kar S, McCue K, Kuchenbaecker K, Michailidou K, Tyrer J, Beesley J, Ramus SJ, Li Q, Delgado MK, et al. 2016 Functional mechanisms underlying pleiotropic risk alleles at the $19 \mathrm{p} 13.1$ breast-ovarian cancer susceptibility locus. Nature Communications [in press].

Lecarpentier J, Nogues C, Mouret-Fourme E, Stoppa-Lyonnet D, Lasset C, Caron O, Fricker JP, Gladieff L, Faivre L, Sobol H, et al. 2011 Variation in breast cancer risk with mutation position, smoking, alcohol, and chest X-ray history, in the French National BRCA1/2 carrier cohort (GENEPSO). Breast Cancer Research and Treatment 130 927-938. (doi:10.1007/s10549-011-1655-3)

Lecarpentier J, Nogues C, Mouret-Fourme E, Gauthier-Villars M, Lasset C, Fricker JP, Caron O, Stoppa-Lyonnet D, Berthet P, Faivre L, et al. 2012 Variation in breast cancer risk associated with factors related to pregnancies according to truncating mutation location, in the French National BRCA1 and BRCA2 mutations carrier cohort (GENEPSO). Breast Cancer Research 14 R99. (doi:10.1186/bcr3218)

Long J, Cai Q, Sung H, Shi J, Zhang B, Choi JY, Wen W, Delahanty RJ, Lu W, Gao YT, et al. 2012 Genome-wide association study in east Asians identifies novel susceptibility loci for breast cancer. PLoS Genetics 8 e1002532. (doi:10.1371/journal.pgen.1002532)

Mavaddat N, Pharoah PD, Blows F, Driver KE, Provenzano E, Thompson D, Macinnis RJ, Shah M, Team S, Easton DF, et al. 2010 Familial relative risks for breast cancer by pathological subtype: a population-based cohort study. Breast Cancer Research 12 R10. (doi:10.1186/bcr2476)

Mavaddat N, Barrowdale D, Andrulis IL, Domchek SM, Eccles D, Nevanlinna H, Ramus SJ, Spurdle A, Robson M, Sherman M, et al. 2012 Pathology of breast and ovarian cancers among BRCA1 and BRCA2 mutation carriers: results from the Consortium of Investigators of Modifiers of BRCA1/2 (CIMBA). Cancer Epidemiology Biomarkers \& Prevention 21 134-147. (doi:10.1158/1055-9965.epi-11-0775)

Mavaddat N, Peock S, Frost D, Ellis S, Platte R, Fineberg E, Evans DG, Izatt L, Eeles RA, Adlard J, et al. 2013 Cancer risks for BRCA1 and BRCA2 mutation carriers: results from prospective analysis of EMBRACE. Journal of National Cancer Institute 105 812-822. (doi:10.1093/jnci/djt095)

Mavaddat N, Pharoah PD, Michailidou K, Tyrer J, Brook MN, Bolla MK, Wang Q, Dennis J, Dunning AM, Shah M, et al. 2015 Prediction of breast cancer risk based on profiling with common genetic variants. Journal of National Cancer Institute $\mathbf{1 0 7}$.

McCormack VA \& dos Santos Silva I 2006 Breast density and parenchymal patterns as markers of breast cancer risk: a metaanalysis. Cancer Epidemiology Biomarkers \& Prevention 15 1159-1169. (doi:10.1158/1055-9965.epi-06-0034)

McLaughlin JR, Risch HA, Lubinski J, Moller P, Ghadirian P, Lynch H, Karlan B, Fishman D, Rosen B, Neuhausen SL, et al. 2007 Reproductive risk factors for ovarian cancer in carriers of BRCA1 or BRCA2 mutations: a case-control study. Lancet Oncology 8 26-34. (doi:10.1016/S1470-2045(06)70983-4)

Meyer KB, O’Reilly M, Michailidou K, Carlebur S, Edwards SL, French JD, Prathalingham R, Dennis J, Bolla MK, Wang Q, et al. 2013 Fine-scale mapping of the FGFR2 breast cancer risk locus: putative functional variants differentially bind FOXA1 and E2F1. American Journal of Human Genetics 93 1046-1060. (doi:10.1016/j. ajhg.2013.10.026)

Michailidou K, Hall P, Gonzalez-Neira A, Ghoussaini M, Dennis J, Milne RL, Schmidt MK, Chang-Claude J, Bojesen SE, Bolla MK, et al. 2013 Large-scale genotyping identifies 41 new loci associated with breast cancer risk. Nature Genetics 45 353-361. (doi:10.1038/ng.2563)

Michailidou K, Beesley J, Lindstrom S, Canisius S, Dennis J, Lush MJ, Maranian MJ, Bolla MK, Wang Q, Shah M, et al. 2015 Genome-wide association analysis of more than 120,000 individuals identifies 15 new susceptibility loci for breast cancer. Nature Genetics 47 373-380. (doi:10.1038/ng.3242)

Milne RL \& Antoniou AC 2011 Genetic modifiers of cancer risk for BRCA1 and BRCA2 mutation carriers. Annals of Oncology 22 i11-i17. (doi:10.1093/annonc/mdq660)

Milne RL, Osorio A, Cajal TR, Vega A, Llort G, de la Hoya M, Diez O, Alonso MC, Lazaro C, Blanco I, et al. 2008 The average cumulative risks of breast and ovarian cancer for carriers of mutations in BRCA1 and BRCA2 attending genetic counseling units in Spain. Clinical Cancer Research 14 2861-2869. (doi:10.1158/1078-0432. CCR-07-4436) 
Milne RL, Gaudet MM, Spurdle AB, Fasching PA, Couch FJ, Benitez J, Arias Perez JI, Zamora MP, Malats N, Dos Santos Silva I, et al. 2010 a Assessing interactions between the associations of common genetic susceptibility variants, reproductive history and body mass index with breast cancer risk in the breast cancer association consortium: a combined case-control study. Breast Cancer Research 12 R110. (doi:10.1186/bcr2797)

Milne RL, Osorio A, Cajal T, Baiget M, Lasa A, Diaz-Rubio E, de la Hoya M, Caldes T, Teule A, Lazaro C, et al. 2010b Parity and the risk of breast and ovarian cancer in BRCA1 and BRCA2 mutation carriers. Breast Cancer Research and Treatment 119 221-232. (doi:10.1007/s10549-009-0394-1)

Milne RL, Burwinkel B, Michailidou K, Arias-Perez JI, Zamora MP, Menendez-Rodriguez P, Hardisson D, Mendiola M, Gonzalez-Neira A Pita G, et al. 2014a Common non-synonymous SNPs associated with breast cancer susceptibility: findings from the Breast Cancer Association Consortium. Human Molecular Genetics 23 6096-6111. (doi:10.1093/hmg/ddu311)

Milne RL, Herranz J, Michailidou K, Dennis J, Tyrer JP, Zamora MP, Arias-Perez JI, Gonzalez-Neira A, Pita G, Alonso MR, et al. 2014b A large-scale assessment of two-way SNP interactions in breast cancer susceptibility using 46,450 cases and 42,461 controls from the breast cancer association consortium. Human Molecular Genetics 23 1934-1946. (doi:10.1093/hmg/ddt581)

Mitchell G, Antoniou AC, Warren R, Peock S, Brown J, Davies R, Mattison J, Cook M, Warsi I, Evans DG, et al. 2006 Mammographic density and breast cancer risk in BRCA1 and BRCA2 mutation carriers. Cancer Research 66 1866-1872. (doi:10.1158/0008-5472. CAN-05-3368)

Nakamura S, Kwong A, Kim SW, Iau P, Patmasiriwat P, Dofitas R, Aryandono T, Hu Z, Huang CS, Ginsburg O, et al. 2016 Current status of the management of hereditary breast and ovarian cancer in Asia: first report by the Asian BRCA Consortium. Public Health Genomics 19 53-60. (doi:10.1159/000441714)

Narod SA, Brunet JS, Ghadirian P, Robson M, Heimdal K, Neuhausen SL, Stoppa-Lyonnet D, Lerman C, Pasini B, de los RP, et al. 2000 Tamoxifen and risk of contralateral breast cancer in BRCA1 and BRCA2 mutation carriers: a case-control study. Hereditary Breast Cancer Clinical Study Group. Lancet 356 1876-1881. (doi:10.1016/ S0140-6736(00)03258-X)

Narod SA, Sun P \& Risch HA 2001 Ovarian cancer, oral contraceptives, and BRCA mutations. New England Journal of Medicine $\mathbf{3 4 5}$ 1706-1707. (doi:10.1056/NEJM200112063452312)

Narod SA, Dube MP, Klijn J, Lubinski J, Lynch HT, Ghadirian P, Provencher D, Heimdal K, Moller P, Robson M, et al. 2002 Oral contraceptives and the risk of breast cancer in BRCA1 and BRCA2 mutation carriers. Journal of National Cancer Institute 94 1773-1779. (doi:10.1093/jnci/94.23.1773)

Nickels S, Truong T, Hein R, Stevens K, Buck K, Behrens S, Eilber U, Schmidt M, Haberle L, Vrieling A, et al. 2013 Evidence of gene-environment interactions between common breast cancer susceptibility loci and established environmental risk factors. PLoS Genetics 9 e1003284. (doi:10.1371/journal. pgen.1003284)

Orr N, Dudbridge F, Dryden N, Maguire S, Novo D, Perrakis E, Johnson N, Ghoussaini M, Hopper JL, Southey MC, et al. 2015 Fine-mapping identifies two additional breast cancer susceptibility loci at 9q31.2. Human Molecular Genetics 24 2966-2984. (doi:10.1093/hmg/ddv035)

Parker WH, Jacoby V, Shoupe D \& Rocca W 2009 Effect of bilateral oophorectomy on women's long-term health. Women's Health $\mathbf{5}$ 565-576. (doi:10.2217/whe.09.42)

Passaperuma K, Warner E, Hill KA, Gunasekara A \& Yaffe MJ 2010 Is mammographic breast density a breast cancer risk factor in women with BRCA mutations? Journal of Clinical Oncology 28 3779-3783. (doi:10.1200/JCO.2009.27.5933)
Permuth-Wey J, Lawrenson K, Shen HC, Velkova A, Tyrer JP, Chen Z, Lin HY, Chen YA, Tsai YY, Qu X, et al. 2013 Identification and molecular characterization of a new ovarian cancer susceptibility locus at 17q21.31. Nature Communications 4 1627. (doi:10.1038/ ncomms2613)

Peto J, Collins N, Barfoot R, Seal S, Warren W, Rahman N, Easton DF, Evans C, Deacon J \& Stratton MR 1999 Prevalence of BRCA1 and BRCA2 gene mutations in patients with early-onset breast cancer. Journal of National Cancer Institute 91 943-949. (doi:10.1093/ jnci/91.11.943)

Pharoah PD, Tsai YY, Ramus SJ, Phelan CM, Goode EL, Lawrenson K, Buckley M, Fridley BL, Tyrer JP, Shen H, et al. 2013 GWAS meta-analysis and replication identifies three new susceptibility loci for ovarian cancer. Nature Genetics 45 362-370, 370e361-362. (doi:10.1038/ng.2564)

Phillips KA, Butow PN, Stewart AE, Chang JH, Weideman PC, Price MA, McLachlan SA, Lindeman GJ, McKay MJ, Friedlander ML, et al. 2005 Predictors of participation in clinical and psychosocial follow-up of the kConFab breast cancer family cohort. Familial Cancer 4 105-113. (doi:10.1007/s10689-004-6129-x)

Phillips KA, Milne RL, Rookus MA, Daly MB, Antoniou AC, Peock S, Frost D, Easton DF, Ellis S, Friedlander ML, et al. 2013 Tamoxifen and risk of contralateral breast cancer for BRCA1 and BRCA2 mutation carriers. Journal of Clinical Oncology 31 3091-3099. (doi:10.1200/JCO.2012.47.8313)

Ramon YCT, Chirivella I, Miranda J, Teule A, Izquierdo A, Balmana J, Sanchez-Heras AB, Llort G, Fisas D, Lope V, et al. 2015 Mammographic density and breast cancer in women from high risk families. Breast Cancer Research 17 93. (doi:10.1186/s13058015-0604-1)

Ramus SJ, Kartsonaki C, Gayther SA, Pharoah PD, Sinilnikova OM, Beesley J, Chen X, McGuffog L, Healey S, Couch FJ, et al. 2010 Genetic variation at 9p22.2 and ovarian cancer risk for BRCA1 and BRCA2 mutation carriers. Journal of National Cancer Institute 103 105-116. (doi:10.1093/jnci/djq494)

Ramus SJ, Antoniou AC, Kuchenbaecker KB, Soucy P, Beesley J, Chen X, McGuffog L, Sinilnikova OM, Healey S, Barrowdale D, et al. 2012 Ovarian cancer susceptibility alleles and risk of ovarian cancer in BRCA1 and BRCA2 mutation carriers. Human Mutation 33 690-702. (doi:10.1002/humu.22025)

Rebbeck TR, Levin AM, Eisen A, Snyder C, Watson P, Cannon-Albright L, Isaacs C, Olopade O, Garber JE, Godwin AK, et al. 1999 Breast cancer risk after bilateral prophylactic oophorectomy in BRCA1 mutation carriers. Journal of National Cancer Institute 91 1475-1479. (doi:10.1093/jnci/91.17.1475)

Rebbeck TR, Lynch HT, Neuhausen SL, Narod SA, Van't Veer L, Garber JE, Evans G, Isaacs C, Daly MB, Matloff E, et al. 2002 Prophylactic oophorectomy in carriers of BRCA1 or BRCA2 mutations. New England Journal of Medicine 346 1616-1622. (doi:10.1056/NEJMoa012158)

Rebbeck TR, Mitra N, Wan F, Sinilnikova OM, Healey S, McGuffog L, Mazoyer S, Chenevix-Trench G, Easton DF, Antoniou AC, et al. 2015 Association of type and location of BRCA1 and BRCA2 mutations with risk of breast and ovarian cancer. JAMA 313 1347-1361. (doi:10.1001/jama.2014.5985)

Risch HA, McLaughlin JR, Cole DE, Rosen B, Bradley L, Kwan E, Jack E, Vesprini DJ, Kuperstein G, Abrahamson JL, et al. 2001 Prevalence and penetrance of germline BRCA1 and BRCA2 mutations in a population series of 649 women with ovarian cancer. American Journal of Human Genetics 68 700-710. (doi:10.1086/318787)

Rivera CM, Grossardt BR, Rhodes DJ, Brown RD Jr, Roger VL, Melton LJ 3rd \& Rocca WA 2009a Increased cardiovascular mortality after early bilateral oophorectomy. Menopause 16 15-23. (doi:10.1097/ gme.0b013e31818888f7)

Rivera CM, Grossardt BR, Rhodes DJ \& Rocca WA 2009b Increased mortality for neurological and mental diseases following early 
bilateral oophorectomy. Neuroepidemiology 33 32-40. (doi:10.1159/000211951)

Rudolph A, Milne RL, Truong T, Knight JA, Seibold P, Flesch-Janys D, Behrens S, Eilber U, Bolla MK, Wang Q, et al. 2015 Investigation of gene-environment interactions between 47 newly identified breast cancer susceptibility loci and environmental risk factors. International Journal of Cancer 136 E685-E696. (doi:10.1002/ijc.29188)

Senst N, Llacuachaqui M, Lubinski J, Lynch H, Armel S, Neuhausen S, Ghadirian P, Sun P, Narod SA \& Hereditary Breast Cancer Study Group 2013 Parental origin of mutation and the risk of breast cancer in a prospective study of women with a BRCA1 or BRCA2 mutation. Clinical Genetics 84 43-46. (doi:10.1111/cge.12037)

Shen H, Fridley BL, Song H, Lawrenson K, Cunningham JM, Ramus SJ, Cicek MS, Tyrer J, Stram D, Larson MC, et al. 2013 Epigenetic analysis leads to identification of HNF1B as a subtype-specific susceptibility gene for ovarian cancer. Nature Communications 4 1628. (doi:10.1038/ncomms2629)

Siddiq A, Couch FJ, Chen GK, Lindstrom S, Eccles D, Millikan RC, Michailidou K, Stram DO, Beckmann L, Rhie SK, et al. 2012 A meta-analysis of genome-wide association studies of breast cancer identifies two novel susceptibility loci at 6q14 and 20q11. Human Molecular Genetics 21 5373-5384. (doi:10.1093/hmg/dds381)

Simchoni S, Friedman E, Kaufman B, Gershoni-Baruch R, Orr-Urtreger A, Kedar-Barnes I, Shiri-Sverdlov R, Dagan E, Tsabari S, Shohat M, et al. 2006 Familial clustering of site-specific cancer risks associated with BRCA1 and BRCA2 mutations in the Ashkenazi Jewish population. PNAS 103 3770-3774. (doi:10.1073/pnas.0511301103)

Song H, Ramus SJ, Tyrer J, Bolton KL, Gentry-Maharaj A, Wozniak E, Anton-Culver H, Chang-Claude J, Cramer DW, Dicioccio R, et al. 2009 A genome-wide association study identifies a new ovarian cancer susceptibility locus on 9p22.2. Nature Genetics 41 996-1000. (doi:10.1038/ng.424)

Song H, Cicek MS, Dicks E, Harrington P, Ramus SJ, Cunningham JM, Fridley BL, Tyrer JP, Alsop J, Jimenez-Linan M, et al. 2014 The contribution of deleterious germline mutations in BRCA1, BRCA2 and the mismatch repair genes to ovarian cancer in the population. Human Molecular Genetics 23 4703-4709. (doi:10.1093/ $\mathrm{hmg} / \mathrm{ddu} 172)$

Stacey SN, Manolescu A, Sulem P, Rafnar T, Gudmundsson J, Gudjonsson SA, Masson G, Jakobsdottir M, Thorlacius S, Helgason A, et al. 2007 Common variants on chromosomes 2q35 and $16 \mathrm{q} 12$ confer susceptibility to estrogen receptor-positive breast cancer. Nature Genetics 39 865-869. (doi:10.1095/ biolreprod.111.093252)

Stacey SN, Manolescu A, Sulem P, Thorlacius S, Gudjonsson SA, Jonsson GF, Jakobsdottir M, Bergthorsson JT, Gudmundsson J, Aben KK, et al. 2008 Common variants on chromosome $5 \mathrm{p} 12$ confer susceptibility to estrogen receptor-positive breast cancer. Nature Genetics 40 703-706. (doi:10.1038/ng.131)

Thomas G, Jacobs KB, Kraft P, Yeager M, Wacholder S, Cox DG, Hankinson SE, Hutchinson A, Wang Z, Yu K, et al. 2009 A multistage genome-wide association study in breast cancer identifies two new risk alleles at 1p11.2 and 14q24.1 (RAD51L1). Nature Genetics $\mathbf{4 1}$ 579-584. (doi:10.1038/ng.353)

Thompson D, Easton D \& Breast Cancer Linkage Consortium 2001 Variation in cancer risks, by mutation position, in BRCA2 mutation carriers. American Journal of Human Genetics 68 410-419. (doi:10.1086/318181)

Thompson D, Easton D \& Breast Cancer Linkage Consortium 2002 Variation in BRCA1 cancer risks by mutation position. Cancer Epidemiology Biomarkers \& Prevention 11 329-336. (doi:10.1210/ en.2002-220652)

Travis RC, Reeves GK, Green J, Bull D, Tipper SJ, Baker K, Beral V, Peto R, Bell J, Zelenika D, et al. 2010 Gene-environment interactions in 7610 women with breast cancer: prospective evidence from the Million Women Study. Lancet 375 2143-2151. (doi:10.1016/S01406736(10)60636-8)

Turnbull C, Ahmed S, Morrison J, Pernet D, Renwick A, Maranian M, Seal S, Ghoussaini M, Hines S, Healey CS, et al. 2010 Genome-wide association study identifies five new breast cancer susceptibility loci. Nature Genetics 42 504-507. (doi:10.1038/ng.586)

Whittemore AS 2007 Assessing environmental modifiers of disease risk associated with rare mutations. Human Heredity 63 134-143. (doi:10.1159/000099185)

Yang XR, Chang-Claude J, Goode EL, Couch FJ, Nevanlinna H, Milne RL, Gaudet M, Schmidt MK, Broeks A, Cox A, et al. 2011 Associations of breast cancer risk factors with tumor subtypes: a pooled analysis from the Breast Cancer Association Consortium studies. Journal of National Cancer Institute 103 250-263. (doi:10.1093/jnci/djq526)

Zheng W, Long J, Gao YT, Li C, Zheng Y, Xiang YB, Wen W, Levy S, Deming SL, Haines JL, et al. 2009 Genome-wide association study identifies a new breast cancer susceptibility locus at 6q25.1. Nature Genetics 41 324-328. (doi:10.1038/ng.318)

Received in final form 12 August 2016

Accepted 15 August 2016

Accepted Preprint published online 15 August 2016
C 2016 Society for Endocrinology Printed in Great Britain
Published by Bioscientifica Ltd 